Review

\title{
Why Do These Microbes Like Me and How Could There Be a Link with Cardiovascular Risk Factors?
}

\author{
Emilia Sawicka-Śmiarowska ${ }^{1,2}$ (D) Anna Moniuszko-Malinowska ${ }^{3}$ and Karol Adam Kamiński ${ }^{1, *(D)}$ \\ 1 Department of Population Medicine and Lifestyle Diseases Prevention, Medical University of Bialystok, \\ 15-269 Bialystok, Poland; emiliasawickak@gmail.com \\ 2 Department of Cardiology, Medical University of Bialystok, 15-276 Bialystok, Poland \\ 3 Department of Infectious Diseases and Neuroinfection, Medical University of Bialystok, \\ 15-540 Bialystok, Poland; anna.moniuszko@umb.edu.pl \\ * Correspondence: fizklin@wp.pl; Tel.: +48-85-8318-656
}

check for updates

Citation: Sawicka-Śmiarowska, E.;

Moniuszko-Malinowska, A.;

Kamiński, K.A. Why Do These

Microbes Like Me and How Could

There Be a Link with Cardiovascular

Risk Factors?. J. Clin. Med. 2022, 11,

599. https://doi.org/10.3390/

jcm11030599

Academic Editors: Marcus Dörr

and Arrigo Cicero

Received: 12 November 2021

Accepted: 21 January 2022

Published: 25 January 2022

Publisher's Note: MDPI stays neutral with regard to jurisdictional claims in published maps and institutional affiliations.

Copyright: (C) 2022 by the authors. Licensee MDPI, Basel, Switzerland. This article is an open access article distributed under the terms and conditions of the Creative Commons Attribution (CC BY) license (https:/ / creativecommons.org/licenses/by/ $4.0 /)$.

\begin{abstract}
Cardiovascular diseases are the most common causes of hospitalization, death, and disability in Europe. Due to high prevalence and ensuing clinical complications, they lead to very high social and economic costs. Despite the knowledge of classical cardiovascular risk factors, there is an urgent need for discovering new factors that may play a role in the development of cardiovascular diseases or potentially influence prognosis. Recently, particular attention has been drawn to the endogenous microflora of the human body, mostly those inhabiting the digestive system. It has been shown that bacteria, along with their host cells, create an interactive ecosystem of interdependencies and relationships. This interplay could influence both the metabolic homeostasis and the immune processes of the host, hence leading to cardiovascular disease development. In this review, we attempt to describe, in the context of cardiovascular risk factors, why particular microbes occur in individuals and how they might influence the host's cardiovascular system in health and disease.
\end{abstract}

Keywords: gut microbiome; heart; cardiovascular risk factors; cardiovascular diseases; cardiovascular system

\section{Introduction}

Cardiovascular diseases lead to more than 16 million deaths worldwide annually, including 4 million in Europe [1-3]. It is well known that cardiovascular diseases are associated with several nonmodifiable risk factors, including age, male gender, and genetic background, as well as modifiable ones, such as lack of physical activity, improper diet, polluted environment, smoking, and other indicators of an unhealthy lifestyle [4-6].

It should be emphasized that despite the knowledge of classical cardiovascular risk factors, the morbidity and mortality in this group of diseases remain high [7]. Consequently, it is necessary to seek new factors that may play a role in the development of cardiovascular diseases. Emerging evidence from the literature suggests that the endogenous microflora of the human body (especially microbiota inhabiting the digestive system) might be involved in many of these crucial physiological and pathological processes [8-13]. It has been shown that bacteria form an interactive ecosystem of interdependencies and relationships with their host cells (in the majority, in the form of mutualism and commensalism) [14-16]. This interplay could influence both the metabolic homeostasis and the immune processes of the host, thereby becoming an important part of the pathogenic process [17].

In this review, we attempt to describe why particular microbes might occur in individuals in the context of both modifiable and nonmodifiable cardiovascular risk factors and how they could influence the host's cardiovascular system. Furthermore, we posit that some of the effects exhibited by the above-mentioned risk factors may in fact be mediated by changes in the microbiome (Tables 1 and 2) [18]. 
Table 1. Association of microbiome with modifiable risk factors.

\begin{tabular}{|c|c|c|c|}
\hline Risk Factor & & Increase In & Decrease In \\
\hline \multirow[b]{2}{*}{ Overweight and obesity } & Observational study: & Firmicutes / Bacteroidetes ratio [19] & $\begin{array}{l}\text { - } \quad \text { Gut microbiome } \\
\text { diversity and richness [20] }\end{array}$ \\
\hline & Interventional study: & $\begin{array}{l}\text { - } \quad \text { Phylum Bacteroidetes: transmitted from lean mice [21] } \\
\text { - } \quad \text { Phylum Actinobacteria: genus Bifidobacterium in } \\
\text { probiotics group [22] } \\
\text { - After weight reduction: total bacterial abundance, } \\
\text { Lactobacilli, Clostridium cluster IV, Faecalibacterium } \\
\text { prausnitzii, Archaea, Akkermansia [23] }\end{array}$ & $\begin{array}{l}\text { - Phylum Bacteroidetes: Bacteroides } \\
\text { vulgates in probiotics group [22] } \\
\text { After weight reduction: } \\
\text { Firmicutes / Bacteroidetes ratio } \\
\text { Clostridium cluster XIVa [23] }\end{array}$ \\
\hline \multirow[t]{2}{*}{$\begin{array}{l}\text { Cholesterol-rich } \\
\text { lipoprotein metabolism }\end{array}$} & Observational study: & 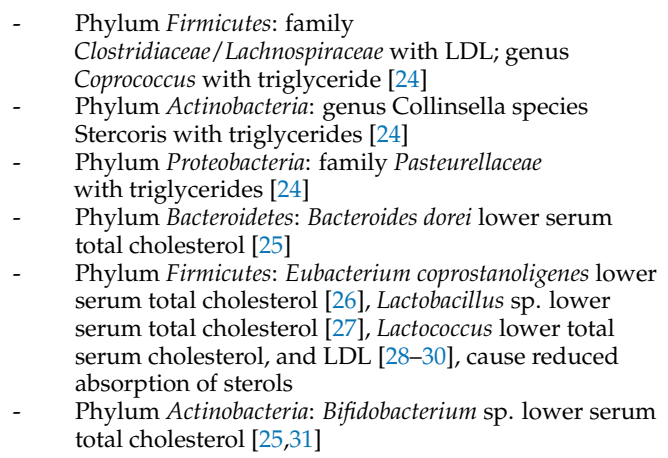 & Richness and diversity [32] \\
\hline & Interventional study: & $\begin{array}{l}\text { - Phylum Proteobacteria: Desulfovibrionaceae in diet } \\
\text { enriched with bile acid and lard and palm oil in mice } \\
\text { model, Ruminococcaceae diet enriched with lard [33] }\end{array}$ & $\begin{array}{l}\text { - } \\
\text { Prylum Firmicutes: } \\
\text { with bile acid and lard and palm oil } \\
\text { in mice model, Lachnospiraceae in } \\
\text { diet enriched with lard [33] } \\
\text { Phylum Firmicutes: Lactococcus } \\
\text { lower total serum cholesterol and } \\
\text { LDL [28-30], cause reduced sterols } \\
\text { absorption [31,34]; Enterococcus } \\
\text { faecium lower total serum } \\
\text { cholesterol and LDL [28-30] }\end{array}$ \\
\hline Tobacco smoking & Observational study: & $\begin{array}{ll}\text { - } & \text { Phylum Proteobacteria: [35]; Alphaproteobacteria [36] } \\
\text { - } & \text { Phylum Bacteroidetes: genera Bacteroides and } \\
\text { Prevotella [35,37]; Prevotella in electronic cigarettes [38]; } \\
\text { genus Bacteroides in 6-month-old infants [39] } \\
\text { Phylum Firmicutes: genus Clostridium [35]; } \\
\text { Erysipelotrichai-to-Catenibacterium [36]; Ruminococcus in } \\
\text { neonates [39]; genus Staphylococcus in } \\
\text { 6-month-old infants [39] } \\
\text { Increased gut bacterial richness, particularly Firmicutes } \\
\text { in 3-month-old infants [39] } \\
\text { - Phylum Verrucomicrobia: Akkermansia in neonates [39] }\end{array}$ & $\begin{array}{ll}\text { - } & \text { Gut microbiome diversity [35] } \\
\text { - } & \text { Phylum Actinobacteria: } \\
\text { - } & \text { genus Bifidobacteria [35] } \\
\text { Phylum Firmicutes: } \\
\text { genus Lactococcus [35] } \\
\text { - } \quad \text { Phylum Proteobacteria [37] } \\
\text { - } & \begin{array}{l}\text { Phylum Bacteroidetes: Bacteroides in } \\
\text { electronic cigarettes [38] }\end{array}\end{array}$ \\
\hline \multirow[t]{2}{*}{ Physical activity } & Observational study: & $\begin{array}{ll}\text { - } & \text { Gut microbiome diversity [40] } \\
\text { - } & 48 \text { taxa vs. high-BMI controls [40] } \\
\text { - } & 40 \text { taxa vs. low-BMI controls [40] } \\
\text { - } & \text { Phylum Verrucomicrobia: Akkermansia [41-43] } \\
\text { - } & \text { Phylum Firmicutes: Roseburia hominis, } \\
\text { - } & \text { Faecalibacterium prausnitzii [43] } \\
\text { Phylum Bacteroidetes: genus Bacteroides [44] }\end{array}$ & $\begin{array}{l}\text { Phylum Bacteroidetes vs. } \\
\text { high-BMI controls [40] } \\
\text { Phylum Bacteroidetes: Bacteroides vs. } \\
\text { low-BMI controls [40] } \\
\text { Phylum Firmicutes: genus } \\
\text { Lactobacillus vs. } \\
\text { low-BMI controls [40] }\end{array}$ \\
\hline & Interventional study: & Bacteroidetes [45] & Firmicutes / Bacteroidetes ratio [45] \\
\hline
\end{tabular}


Table 2. Association of microbiome with non-modifiable risk factors.

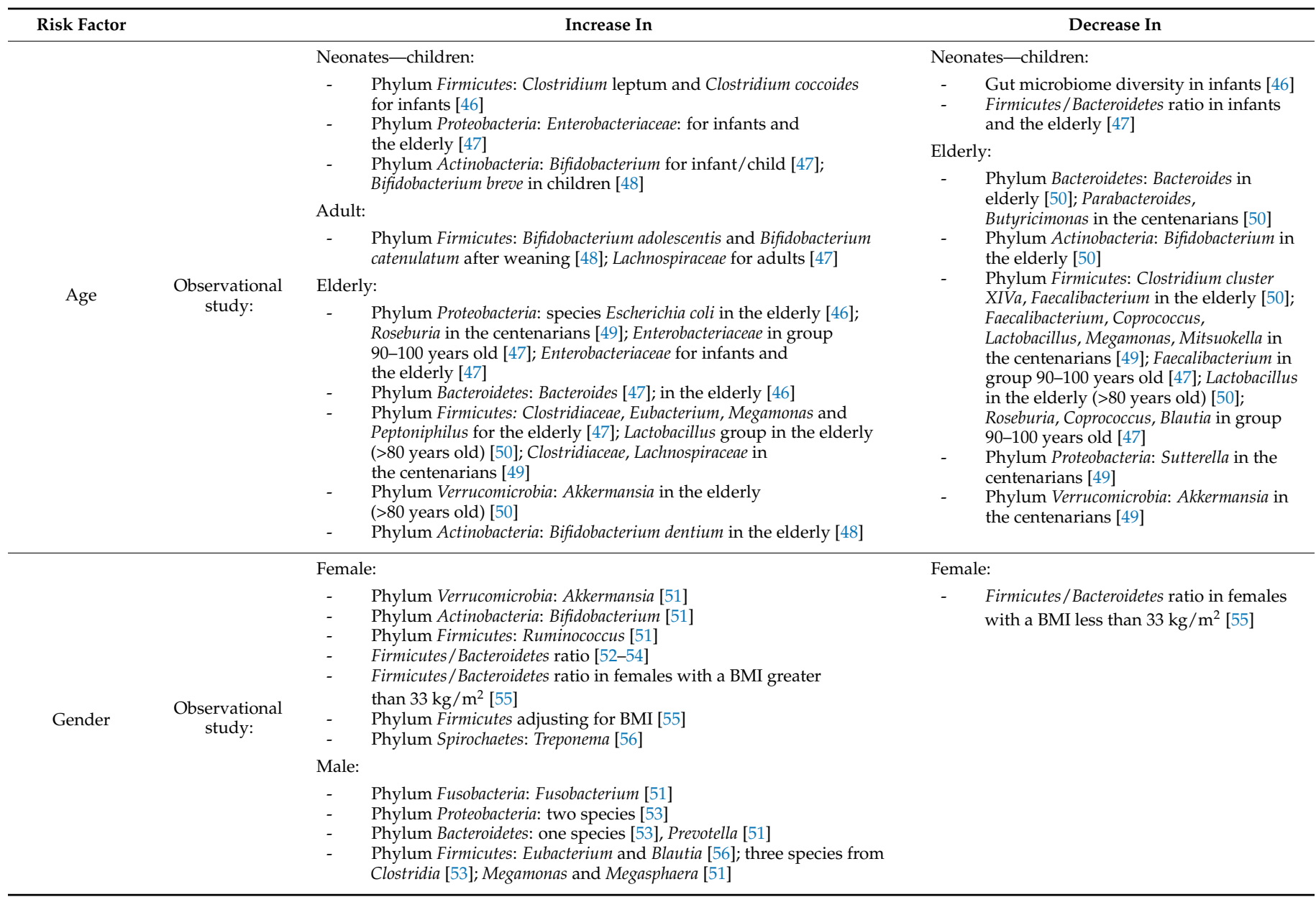

\section{Association of the Microbiome with Modifiable Risk Factors}

\subsection{Overweight and Obesity}

Overweight and obesity have been linked to many cardiovascular diseases, including, among others, coronary artery disease, heart failure, and stroke $[57,58]$. Excessive body weight might be mediated by direct effects such as structural and functional adaptations of the cardiovascular system and adipokine effects on inflammation and vascular homeostasis [58]. Indirect effects in overweight and obese individuals might be related to a higher prevalence of various diseases, such as insulin resistance, hyperglycemia, hypertension, and dyslipidemia [58].

Recently, particular attention has been paid to the role of the gut microbiome in maintaining weight. Gut microbiota were proven to play an important role in the absorption, storage, and expenditure of energy obtained from dietary intake [59]. This effect might be related to short-chain fatty acid production, the stimulation of hormones, chronic low-grade inflammation, lipoprotein, bile acid metabolism, and increased endocannabinoid receptor system activity [20].

Although the findings from animal and human studies differ, the most common result is an increase in the Firmicutes/Bacteroidetes ratio [18,60] and a reduction in microbial diversity and richness [61]. Furthermore, it was proven that Firmicutes/Bacteroidetes ratio was significantly associated with BMI, and this association continued to be significant after adjusting for confounders such as age, sex, tobacco smoking, and physical activity [19]. 
Ridaura et al. showed that cohousing mice harboring an obese twin's microbiota with mice harboring a lean twin's microbiota, due to the transmission of Bacteroidetes from lean mice, prevents abnormally high BMI development and obesity-associated metabolic phenotypes in obese cage mates [21]. A similar proof-of-concept study of the gut microbiome transfer effect on BMI is currently being conducted on humans [62].

A single-center, double-blind, placebo-controlled trial of two separate child cohorts who were overweight or obese revealed that the group given oligofructose-enriched inulin (probiotics) or maltodextrin as a placebo was characterized as having an increase in the genus Bifidobacterium and a decrease in Bacteroides vulgatus [22]. Despite the mentioned shifts in the gut microbiome due to probiotics supplementation [22], the results of the metanalyses published in 2015 [63] and in 2019 [64] did not confirm the thesis that pre- and probiotics had an effect on body weight or BMI. In the interventional study, in which obese individuals received a dietary intervention for over three months, after weight reduction, an increase in total bacterial abundance was revealed [23]. Furthermore, Lactobacilli, Clostridium cluster IV, Faecalibacterium prausnitzii, Archaea, and Akkermansia significantly increased, while Clostridium cluster XIVa and the Firmicutes / Bacteroidetes ratio decreased [23].

What Might This Mean for the Heart?

Evidence from the literature suggests that SCFA (short-chain fatty acid) production by bacteria may significantly contribute to an altered energy balance [65-67]. In the study of Schwiertz A. et al., total fecal SCFAs were higher in obese compared to lean subjects [67]. Additionally, the propionate concentration increased significantly from lean to obese subjects [67]. SCFA, except for succinate, seems to have a beneficial influence on many cardiovascular diseases [68]. Acetate was proven to lower both the heart rate (lowering sympathetic activity) and mean arterial pressure in vivo in radiotelemetry-implanted mice [69]. Additionally, propionate seems to participate in blood pressure regulation (reduction via GPR41 due to its influence on vascular contractibility and an increase via OLFR78 due to rennin production and release) $[68,70]$. This SCFA also promotes anti-inflammatory Treg cells and therefore may also reduce hypertension, atherosclerosis, and cardiac hypertrophy [71]. Propionate also participates in H3Lys23 histone propionylation, which is involved in cardiac development [68].

Oral supplementation of butyrate by nuclear factor $\mathrm{k}-\mathrm{B}$ inhibition and decreasing the pro-inflammatory state might slow atherosclerosis progression [68,72]. This SCFA also suppresses histone deacetylase to reduce myocardial remodeling in the diabetic heart [68,73].

\subsection{Cholesterol-Rich Lipoprotein Metabolism}

The role of lipid metabolism in the human body is complex, and its disturbances have important physiological implications [74]. On the one hand, lipids are the major structural components of cell membranes, energy storage, and regulation molecules [75-77]. On the other hand, it is well known that an abnormal lipid profile, especially a high low-density lipoprotein concentration, is one of the modifiable risk factors leading to cardiovascular diseases [6]. The gut microbiota might both modulate the amount of energy that is extracted from food during digestion and synthesize lipids and metabolites (sphingolipids, sterol, fatty acyls, and glycerolipid synthesis) that may have an impact on human health [75].

In the mice model, in which animals with the presence or absence of gut commensal were fed a diet enriched with bile acids with or without the addition of lard or palm oil, a shift in dominant gut bacterial was observed [33]. In the study, a diet enriched with lard or palm oil caused body weight gain only in mice with the presence of gut commensal [33]. The diet enriched with lard and bile acid was associated with increased microbiome richness [33]. In the study, all types of diet intervention resulted in increased proportions of Desulfovibrionaceae and a lack of Erysipelotrichaceae [33]. The relative abundance of Lachnospiraceae significantly decreased in the diet enriched with lard oil compared to palm oil, whereas Ruminococcaceae increased compared to the control group [33]. Both lard and palm oil dietary interventions resulted in a lower relative abundance of Rikenellaceae [33]. 
In the study of Fu J. et al. based on 893 subjects from the Life-Lines-DEEP population cohort, 114 OUT were associated with triglycerides, and 34 with HDL (high-density lipoproteins) [24]. The family of Clostridiaceae/Lachnospiraceae was particularly associated with LDL, and there was no correlation detected with BMI or other lipids [24]. The family of Pasteurellaceae, genera Coprococcus, and Collinsella species Stercoris were associated with triglyceride levels with a nominal significance to other lipids and had no association with BMI [24]. Furthermore, a cross-validation analysis revealed that the microbiota explain $6 \%$ of the variance in triglycerides and $4 \%$ in HDL, independent of age, sex, and genetic risk factors [24].

It was suggested that the gut microbiome might participate in cholesterol conversion to coprostanol [78]. Individuals with coprostanol-forming gut microbiota have significantly lower fecal cholesterol levels and lower serum total cholesterol [78]. Previously reported coprostanol-forming bacteria are Eubacterium coprostanoligenes, Bacteroides dorei, Lactobacillus sp., and Bifidobacterium sp. [25-27].

Furthermore, the gut microbiome in hypercholesterolemia patients was characterized as having a lower richness and diversity of bacterial communities compared to normocholesterolemic controls [32].

What Might This Mean for the Heart?

There are many ways in which the gut microbiome might play a significant role in the regulation of lipid homeostasis and plasma lipid levels and therefore affect the cardiovascular system $[75,79]$. To reduce cardiovascular risk due to an abnormal serum lipid profile, the gut microbiota has been targeted in dyslipidemia treatment, especially with products enhanced with Lactobacillus spp. [28-31,34]. A meta-analysis focusing on studies using short-chain fatty acids producing the bacteria Lactobacillus formulations found an improvement of LDL and total serum cholesterol but not triglycerides nor HDL [28]. Two randomized, double-blind, placebo-controlled studies showed a $4.4 \%$ total cholesterol and 6.2\% LDL reduction caused by Lactobacillus acidophilus or Enterococcus faecium in subjects with a normal lipid profile and medium to moderate hypercholesterolemia $[29,30]$. Furthermore, Lactobacillus reuteri was associated with increased intraluminal bile acid deconjugation, which leads to reduced absorption of sterols other than cholesterol [34]. One study found an improvement of triglycerides but not cholesterol after short-term Bifidobacteriae and Lactobacilli coadministration in healthy subjects, whereas another study revealed a decrease in LDL, total cholesterol, and triglycerides, whereas there was an increase in HDL when using a Bifidobacterium/yeast extract symbiotic [31]. Furthermore, Liu et al. demonstrated that the cholesterol-lowering effect of eight weeks of rosuvastatin treatment was reflected in microbial alpha-diversity [80].

\subsection{Tobacco Smoking}

There is emerging evidence that tobacco smoking might be related to gut microbiome composition [35]. A few potential mechanisms of this phenomenon were suggested, such as oxidative stress enhancement, Th17 cell-neutrophil axis, alterations of intestinal tight junctions and intestinal mucin composition, and changes in the acid-base balance [35,81]. A review of articles published between 2000 and 2016 indicated that smoking increases the abundance of Proteobacteria and Bacteroidetes phyla (Bacteroides and Prevotella genera) and genus from Firmicutes phylum (Clostridium), with a decrease in Actinobacteria (genus Bifidobacteria) and Firmicutes phyla (genus Lactococcus) [35]. Smoking also decreased the diversity of the intestinal microbiome [35]. Interestingly, a population-based, crosssectional study, using the Healthcare Screening Center cohort and conducted on 758 men, showed that current smokers had an increased proportion of the phylum Bacteroidetes with decreased Firmicutes and-contrary to the previously mentioned article-Proteobacteria compared with people who had never smoked [37]. In the study, differences between former smokers and people who had never smoked were not observed [37]. Another crosssectional study of 249 participants selected from the Health Effects of Arsenic Longitudinal 
Study in Bangladesh revealed that Erysipelotrichi-to-Catenibacterium lineage (Firmicutes phylum) was significantly higher in current smokers compared to never smokers [36]. Furthermore, each of these taxa exhibited a dose-response relationship with packs of cigarettes smoked per day [36]. The odds ratio for the genus Catenibacterium comparing the mean relative abundance in current smokers with that in never smokers was 1.91 and 1.89 for the family Erysipelotrichaceae [36]. Furthermore, the presence of Alphaproteobacteria (from Proteobacteria phylum) was significantly greater when comparing current smokers with never smokers [36]. A dose-response association was observed for each of these bacterial taxa [36]. Interestingly, one of the studies examined not only the influence of tobacco smoking but also electronic cigarettes and revealed changes in Bacteroidetes phylum in the form of an increased relative abundance of Prevotella and decreased Bacteroides compared to controls [38]. This study also suggested that tobacco smoking might have a more severe effect on health than electronic cigarettes [38].

A review of prospective cohort studies that assessed the gut microbiome of 1277 infant/neonatal participants exposed to environmental smoke showed that neonates exposed to environmental smoke present a higher relative abundance of Ruminococcus (Firmicutes phylum) and Akkermansia [39]. Infants exposed to environmental smoke during pregnancy or postnatally have increased gut bacterial richness, particularly Firmicutes at 3 months of age, while 6-month-old infants born to smoking mothers had an increased abundance of Bacteroides and Staphylococcus [39]. Elevated Firmicutes richness at 3 months of age was associated with elevated odds of child overweight and obesity at 1 and 3 years of age [39].

\section{What Might This Mean for the Heart?}

The data from the literature suggest that tobacco smoke might cause dysbiosis and a decrease in gut microbiome richness [35-39]. Tobacco smoking was positively related to Bacteroidetes phylum [35,37-39] and some potentially pathological genera from Firmicutes $[35,36,39]$ and inversely associated with beneficial genera such as Lactococcus [35] and Bifidobacteria [81]. The predominant genera in the human colonic microbiota are antagonistic Bacteroides (linked to a high intake of fat and protein) and Prevotella (linked to plant-rich diets with high levels of complex carbohydrates and fruit and vegetable intake), and interestingly, smoking causes an increase in both of them [35]. A commensal bacterium Bacteroides, in a myocarditis in mice model, triggers a cross-immune response against a bacterial protein and heart epitope, causing cardiomyopathy [82]. Moreover, Prevotella plays an important role in dysbiosis in pre- and hypertension patients [83], high lifetime cardiovascular disease risk [84], and cardiac valve calcification [85]. A positive correlation between Catenibacterium enrichment in current smokers and other unhealthy factors, such as the dietary level of animal fat, was revealed [86]. The study of Nolan-Kenney R. et al. showed a weaker relation in terms of the gut microbiome between former smokers and never smokers than comparing current smokers and never smokers, suggesting a beneficial effect of quitting smoking [36]. Class Alphaproteobacteria, presented in current smokers, consists, among others, of Rickettsiales that are capable of causing serious lesions of the mitral and aortic valves, leading to a need for valve replacement [87]. In a study involving 148 patients undergoing valve replacement, antibodies to Rickettsia spp. were detected in 12 cases [87].

Moreover, studies on newborns and infants suggest that both pre- and postnatal exposure to tobacco resulted in gut microbiome dysbiosis (enrichment in Firmicutes) that favors excessive body weight in children [88].

\subsection{Physical Activity}

Physical activity, leading to improved levels of cardiorespiratory fitness, is crucial in cardiovascular disease prevention [89] and it has been suggested to play a role in shaping the human gut microbiota $[40-45,90,91]$. Clarke S.F. et al. found that the gut microbiota of professional rugby players had greater alpha diversity and, compared to high-BMI controls, greater proportions of 48 taxa, while there was only a reduction in 
Bacteroidetes [40]. Further analysis showed that in the gut microbiome of elite athletes, compared to low-BMI controls, significantly higher proportions of 40 taxa were revealed with lower proportions of Lactobacillaceae, Bacteroides, and Lactobacillus [40]. Interestingly, both athletes and the low-BMI group demonstrated a higher proportion of the Akkermansia genus [41]. Additionally, identified microbiota representing 22 distinct phyla positively correlated with protein consumption and plasma creatine kinase [40]. In a follow-up study, the same group of researchers confirmed the microbial diversity among elite rugby athletes compared to nonnative, age-matched controls and again demonstrated higher levels of Akkermansia [42]. Additionally, active women (performing at least $3 \mathrm{~h}$ of exercise per week) compared with sedentary controls had increased levels of Faecalibacterium prausnitzii, Roseburia hominis, and Akkermansia muciniphila [41,43]. Another study on elderly women claims that aerobic exercise training may increase intestinal Bacteroides in association with improved cardiorespiratory fitness [44]. Two reviews from 2019 identified that the main phylum that respond to exercise is Firmicutes (including SCFA-producing genera from the Firmicutes phylum) [90,91].

In an interventional study on 26 subjects with abnormal glucose metabolism included in training modules, an increasing Bacteroidetes phylum and decreasing Firmicutes/Bacteroidetes ratio were revealed [45].

What Might This Mean for the Heart?

The most important change in gut microbiome composition that might be related to exercise is enrichment in the phylum Firmicutes $[40,90,91]$ and the phylum Verrucomicrobia, which contains only a few described species [41-43]. One of them is Akkermansia that, as previously mentioned, is currently being considered as a next-generation therapeutic agent in obesity $[41,92,93]$. Akkermansia muciniphila-derived extracellular vesicles seem to play a role in the regulation of gut permeability [94]. In a high-fat-diet-induced diabetic mice model, their administration enhanced tight junction function and occludin expression while reducing body weight gain and improving glucose tolerance [94]. Furthermore, not only extracellular vesicles but Akkermansia itself increased tight junction, such as occludin, occludin 4, zonula occludens 1-3, and the expression of Toll-like receptors 2 and 4 that participate in regulating the host immune system [95]. Akkermansia muciniphila also increases the number of goblet cells and mucus secretion, restoring the thickness of the intestinal mucus caused by a high-fat diet [96]. Its low abundance was also related to elevated body weight, blood cholesterol, and fasting blood glucose level [97]. A positive effect on health related to Roseburia enrichment due to exercise might be in relation to the fact that this bacterium in the study conducted on 4672 subjects from 6 different ethnic groups participating in the Healthy Life In an Urban Setting (HELIUS) was proven to be the best predictor from the machine learning model of blood pressure. A higher Roseburia abundance was related to a lower blood pressure [98]. Roseburia plays a role in maintaining gut health due to antimicrobial metabolites and immune defense, such as regulatory T-cell homeostasis, primarily through SCFA production (especially butyrate) [99]. These bacteria affect colonic motility and perform the maintenance of immunity and anti-inflammatory properties [99].

Another potentially positive aspect to the heart might be related to an increase in SCFA-producing genera from the Firmicutes, such as Faecalibacterium prausnitzii [100]. A gut microbiome dysbiosis expressed in the case of this bacteria as a depleted abundance was observed in chronic heart failure patients [101].

\section{Association of the Microbiome with Nonmodifiable Risk Factors}

\subsection{Age}

Emerging evidence from the literature suggests that aging is associated with the evolution of the human gut microbiome [46-50,102-105]. A comparative assessment from 2009 of the human fecal microbiota of infants, adults, and the elderly showed that the microbiota of infants were generally characterized by low levels of total bacteria abundance [46]. Clostrid- 
ium leptum and Clostridium coccoides species were highly represented in the microbiota of infants, while elderly subjects exhibited high levels of Escherichia coli and Bacteroidetes [46]. Moreover, the Firmicutes / Bacteroidetes ratio changes from infants, to adults, to the elderly: $0.4,10.9$, and 0.6, respectively [46]. Another study, based on 367 healthy Japanese subjects between the ages of 0 and 104, showed changes in co-abundance groups (CAGs) related to age [47]. The dominance of Bifidobacterium (phylum Actinobacteria) was revealed for infants/children, whereas Enterobacteriaceae (phylum Proteobacteria) dominance was revealed for infants and the elderly [47]. Furthermore, Lachnospiraceae (phylum Firmicutes) was distinctive for adults and Bacteroides and Eubacterium and Clostridiaceae, Megamonas, and Peptoniphilus (phyla Bacteroidetes, Firmicutes) were distinctive for the elderly [97]. Moreover, sequential changes occurred in the relative abundance of Bacteroides, Lachnospiraceae, and Bifidobacterium in the gut microbiota during childhood and adolescence [47]. Additionally, Salazar N. et al. showed that the presence of the Bacteroides, Bifidobacterium, Faecalibacterium, and Clostridium cluster XIVa decreased with age up to the ages of 66-80, with differences reaching statistical significance for the latter group [50]. Interestingly, the abundance of some of these microorganisms changed again in the very old age group ( $>80$ years), with these older individuals presenting significantly higher counts of Akkermansia and Lactobacillus than adults and the younger elderly [50].

Some authors have tried to identify the gut microbiome profiles responsible for longevity. In 2015, Wang F. et al. compared the gut microbiome of eight centenarians (100-108 years old) with eight younger elderly people (85-99 years old) and eight elderly people (80-92 years old), revealing a decrease in Lactobacillus, Faecalibacterium, Parabacteroides, Butyricimonas, Coprococcus, Megamonas, Mitsuokella, Sutterella, and Akkermansia and an increase in Roseburia and Escherichia [49]. In the study, Ruminococcaceae, Clostridiaceae, and Lachnospiraceae were characterized as age-related operational taxonomic units (OTUs), and the former two were increased in centenarians [49]. Odamaki T. et al. showed a decrease in Faecalibacterium, Roseburia, Coprococcus, and Blautia and an increase in Enterobacteriaceae in the groups of analysis of 90- and 100-year-old subjects [47]. Interestingly, the bifidobacterial capacity to promote longevity by enhancement of bacterial polyamine biosynthesis has been shown in an animal model [103]. Bifidobacterium breve was detected in approximately $70 \%$ of children under 3 years old. Bifidobacterium adolescentis and Bifidobacterium catenulatum groups were predominant after weaning. Bifidobacterium bifidum was detected at almost all ages, from 0 to 104 years. The detection rate of Bifidobacterium dentium was higher in the elderly than in other age groups [48]. In another study, co-cultivating Bifidobacterium species resulted in an increase in the transcription of the gene required for exopolysaccharides biosynthesis [104]. This might influence the interaction between Bifidobacterium and the host, including the ability of commensal bacteria to remain immunologically silent and, in turn, provide pathogen protection [104].

Moreover, a decrease in stool microbial diversity is shown when we consider not chronological but biological age [105]. In one study, the subject frailty index (FI) and chronological age were assigned to low, middle, and high tertiles for OTU differential abundance analysis. Subjects with high frailty index scores, compared with those with a low frailty index, exhibited an increased abundance of the Firmicutes phylum (Coprobacillus, Dialister) and the Saccharibacteria phylum (TM7 candidate-phylum). A high frailty index was associated with a decrease in Bacteroidetes and Proteobacteria phyla (Paraprevotella, Rikenellaceae, and Sutterella, respectively). The middle frailty index, compared with a low frailty index, was associated with greater TM7 candidate-phylum abundance [104]. Furthermore, in the study, authors using the Sparse Inverse Covariance Estimation for Ecological Association and Statistical Inference and Weighted Gene Co-Expression Network Analysis identified modules of coabundant microbial genera related to biological or chronological age [105]. The positively coabundant Eggerthella, Coprobacillus, and Ruminococcus genera were significantly associated with biological age after correction for other confounders, for instance, body mass index, sex, and antibiotic usage in the past 6 months [105]. Therefore, this module might be considered a biological age indicator. 
What Might This Mean for the Heart?

The data from the literature demonstrated that taxa enrichment in elderly people is potentially pathogenic $[106,107]$. The first of them is Escherichia coli, which could be a cause of endocarditis [106]. Clostridium difficile [107] was found on naive pathologically changed heart valves that were explanted [107].

Despite the fact that results from various studies differ in terms of Megamonas abundance in relation to advanced age $[46,49,108]$, this taxon was depleted in heart failure patients [109] and in cardiac valve calcification patients [85]. Furthermore, according to the association with dyslipidemia, Megamonas, among others, was regarded as a potential pathogen for cardiovascular diseases [85].

Additionally, one of the OTUs related to age was Ruminococcaceae [49,51], the taxon connected to a healthy high-fiber diet [49] and enhanced short-chain fatty acid production [109-111]. However, this taxon was also found in the group with a vitamin D concentration $<50 \mathrm{nmol} / \mathrm{L}$ [112].

\subsection{Gender}

The differences in cardiovascular conditions between genders are related to genetic and hormonal differences between women and men [113]. Furthermore, this might be partially related to their distinct gut microbiome profiles [52-56]. Another important finding is the fact that data from the literature suggest that women may harbor a higher Firmicutes / Bacteroidetes ratio than men [52-54] and higher proportions of Firmicutes after adjusting for BMI [55]. Furthermore, among people with a BMI greater than 33, a significantly higher Firmicutes / Bacteroidetes ratio was seen in women compared to men, while the opposite value of the ratio was observed in those with a BMI less than 33 [55]. Other studies showed an increase in Treponema in women and increased Eubacterium and Blautia in men [56]. Furthermore, three species from Clostridia, one from Bacteroidetes, and two from Proteobacteria had a higher abundance in males than in females [53].

Moreover, an analysis conducted on 277 healthy Japanese subjects aged 20-89 years revealed increases in various genera related to age and depending on gender [51]. Increases in Prevotella, Megamonas, Fusobacterium, and Megasphaera were found in males, whereas Bifidobacterium, Ruminococcus, and Akkermansia were found in female subjects [51].

\section{What Might This Mean for the Heart?}

A higher Firmicutes/Bacteroidetes ratio, which was reported in women, is generally considered an indicator of gut dysbiosis. Its elevated value is reported in industrialized diets [56] and many cardiological diseases such as coronary artery disease [114,115] and myocarditis [116]. Bifidobacterium could be both beneficial and unfavorable to our health Increased Bifidobacterium contributes to the generation of favorable microbial metabolites [117], attenuated cardiac injury from ischemia-reperfusion [118] and has been found in heart failure patients [108]. Bifidobacterium is often used as a probiotic and might act via modification of the gut microbiota, competitive adherence to the mucosa and epithelium, strengthening of the gut epithelial barrier, and modulation of the immune system to convey an advantage to the host [119]. Homeostasis with the host might be mediated by Toll-like receptors and nucleotide-binding oligomerization-domain-containing protein-like receptors, nuclear factor-kB, and mitogen-activated protein kinase [119].

Moreover, the depletion of Blautia genera was found in valve calcification [85]. Prevotella was connected to a diet rich in non-digestible carbohydrates, decreasing with elevated alcohol consumption [120], and is associated with pre- and hypertension [83]. 


\section{Firmicutes/Bacteroidetes Ratio}

In the literature, different gut microbiota were related to risk factors, particularly for cardiovascular diseases; however, one of the most common results is a change in the Firmicutes/Bacteroidetes ratio [19,83-87,114-116,121-123]. A higher value was found to be related to abnormal body weight, lack of physical activity, and female gender (Figure 1) $[19,52-54,90,112,113]$. Furthermore, the Firmicutes/Bacteroidetes ratio changes with age (Figure 1) [46].

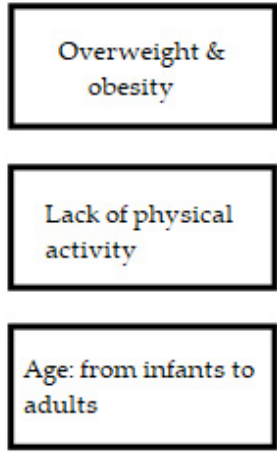

Female gender
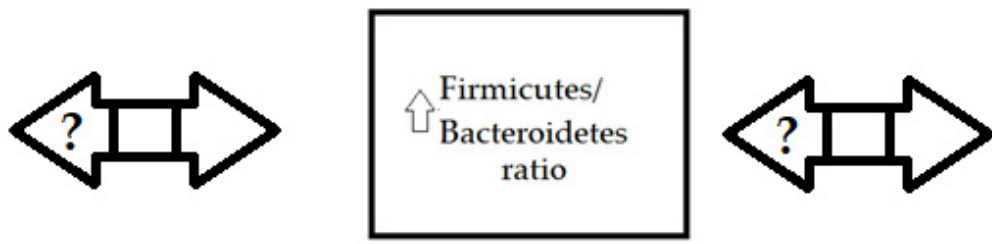

Myocarditis

Potential marker of the development of subclinical cardiovascular disease in type 2 Diabetes

Hypertension

Figure 1. Firmicutes/Bacteroidetes ratio and cardiovascular risk factors and pathologies. Some cardiovascular risk factors influence Firmicutes/Bacteroidetes ratio, and Firmicutes/Bacteroidetes ratio might influence cardiovascular risk factors and cardiovascular pathologies. It is questionable whether a higher Firmicutes/Bacteroidetes ratio is a cause or a result of cardiovascular pathologies and if cardiovascular pathologies could affect Firmicutes/Bacteroidetes ratios.

\section{Short-Chain Fatty Acids and Cardiovascular Risk Factors}

Short-chain fatty acids (SCFAs) are products of the fermentation of non-digestible carbohydrates by the gut microbiota in the human digestive tract [124]. Among them, propionate and butyrate seem to play the most significant health-promoting roles [125]. SCFAs are absorbed by diffusion or via GPR41 and GPR43 in the intestine [126]. A normal colonic epithelium derives $60-70 \%$ of its energy supply from SCFA-butyrate [127]. Propionate is transported to the liver and used as a precursor for gluconeogenesis, liponeogenesis, and protein synthesis [128], while acetate can be used as a substrate for lipogenesis and gluconeogenesis $[125,129]$. SCFAs may also target the liver to reduce hepatic glucose production and lipid accumulation via AMPK activation [126]. SCFAs can directly signal to adipose tissue via GPR43/GPR41 and enhance adipogenesis and uncoupling protein-1 production while restraining lipolysis and inflammation [126]. Furthermore, SCFA might target the brain via GPR41 and also stimulate the production of satiety hormones (glucagon-like peptide 1 and protein YY) production [126]. In the study of Frost G. et al., acetate was shown to accumulate in the hypothalamus and induce acetyl-coenzyme carboxylase activation A, causing a change in the expression profile of regulatory neuropeptides and leading to appetite suppression [130].

In this review, we underlined the fact that some bacteria related to particular risk factors are involved in SCFA production (Figure 2). 

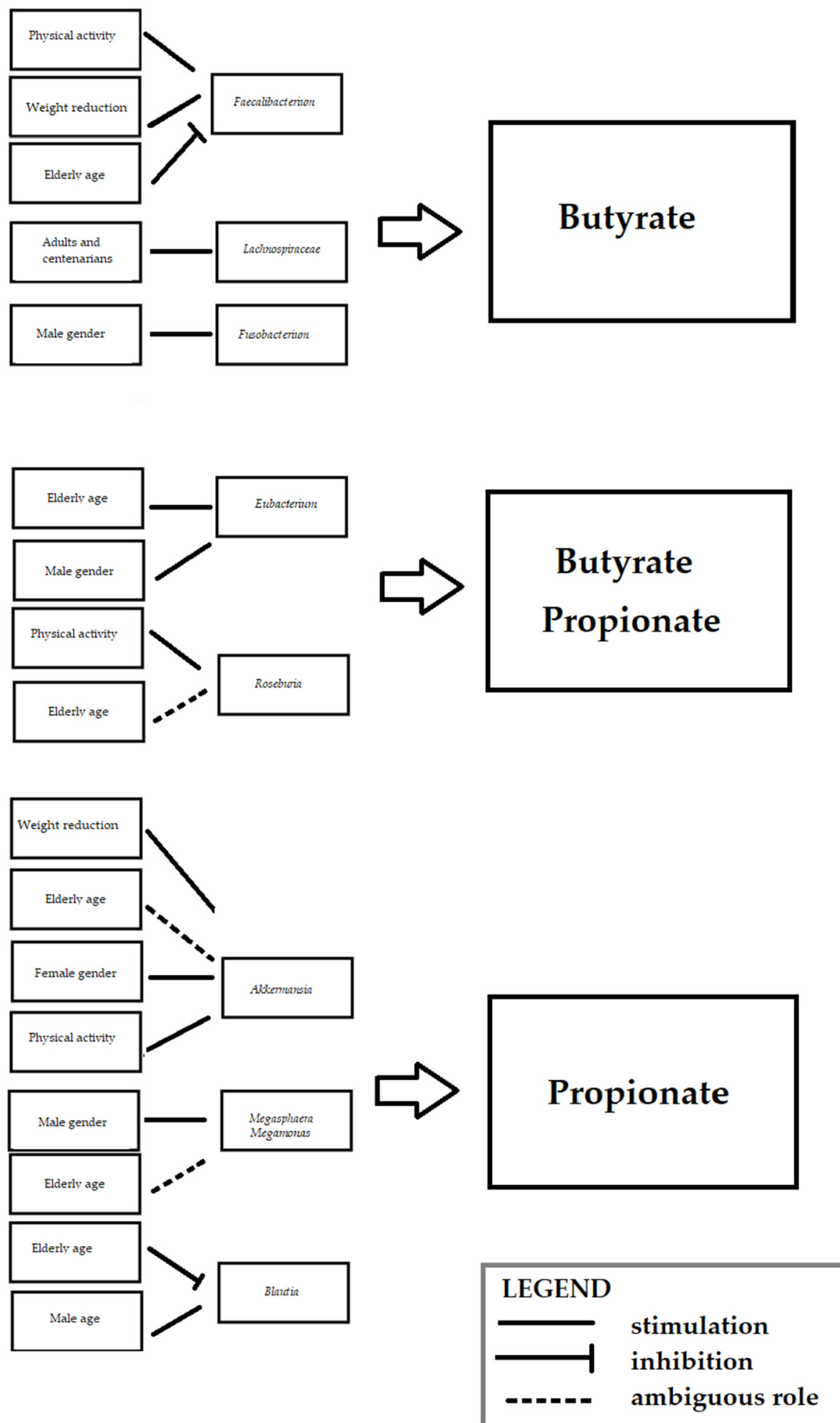

Figure 2. Short-chain fatty acid production potential of listed bacteria and their association with particular cardiovascular risk factors.

\section{Summary}

In this review, we discussed why particular microbes occur in individuals and how they might influence the host's cardiovascular system in health and disease, especially in the context of modifiable and nonmodifiable cardiovascular risk factors. 
We identified many bacteria that are connected to risk factors and responsible for specific diseases; however, the main finding is that the most important factor is the whole gut's microbiome composition and the shifts in it. It is commonly suggested that the Firmicutes / Bacteroidetes ratio is an indicator for gut dysbiosis, and one study found its increase in overweight and obesity and its changes due to aging and gender. Furthermore, we underlined the fact that some bacteria related to cardiovascular risk factors are involved in SCFA production. Despite the enormous knowledge about cardiovascular risk factors and the gut microbiome, some influences, interdependencies, and relationships are still not fully elucidated. Therefore, studies based on a larger population with advanced, novel "omics" methods should be conducted.

\section{Future Area of Research}

It is essential to be aware that the gut microbiome's composition is susceptible to many environmental factors other than those described in this manuscript, for instance, medication, diet [131], and environmental factors (temperature, habits, pollution). Furthermore, it is still not fully elucidated whether changes in the microbiome are a cause or an effect of cardiovascular diseases. To answer this question, prospective cohort studies on large populations examining gut microbiome composition before and after disease onset are necessary. Another important aspect is the incorporation of microbiome analyses in randomized controlled trials. In the future, particular benefits could be obtained from interventional studies on cardiovascular risk factor modification by microbiota transplantation.

Due to the fact that many mechanisms concerning gut microbiota described in this manuscript have only been tested in animal models, the significance of these phenomena should be documented in human models as well, with an emphasis on the distinctiveness of the gut microbiota in individual species.

Author Contributions: Conceptualization, E.S.-Ś., A.M.-M. and K.A.K.; data curation, E.S.-Ś. and K.A.K.; formal analysis, E.S.-Ś. and K.A.K.; funding acquisition, E.S.-Ś., A.M.-M. and K.A.K.; investigation, E.S.Ś. and K.A.K.; project administration, K.A.K.; resources, E.S.-Ś; validation, K.A.K. and A.M.-M.; visualization, E.S.-Ś. and K.A.K.; writing—original draft, E.S.-Ś.; writing-review and editing, E.S.-Ś., A.M.-M. and K.A.K. All authors have read and agreed to the published version of the manuscript.

Funding: This research was funded by National Science Centre, Poland, project No.: 2017/25/N/NZ5/ 02765 and Statutory grants of the Medical University of Bialystok.

Institutional Review Board Statement: Not applicable.

Informed Consent Statement: Not applicable.

Data Availability Statement: Not applicable.

Conflicts of Interest: The authors declare no conflict of interest.

\section{References}

1. Roth, G.A.; Mensah, G.A.; Johnson, C.O.; Addolorato, G.; Ammirati, E.; Baddour, L.M.; Barengo, N.C.; Beaton, A.Z.; Benjamin, E.J.; Benziger, C.P.; et al. Global Burden of Cardiovascular Diseases and Risk Factors, 1990-2019: Update from the GBD 2019 Study. J. Am. Coll. Cardiol. 2020, 76, 2982-3021. [CrossRef] [PubMed]

2. Nichols, M.; Townsend, N.; Scarborough, P.; Rayner, M. Cardiovascular disease in Europe: Epidemiological update. Eur. Heart J. 2013, 34, 3028-3034. [CrossRef] [PubMed]

3. Available online: http://www.ehes.info/manuals/national_manuals/national_manual_Poland_PL.pdf (accessed on 17 August 2021).

4. Al-Kindi, S.G.; Brook, R.D.; Biswal, S.; Rajagopalan, S. Environmental determinants of cardiovascular disease: Lessons learned from air pollution. Nat. Rev. Cardiol. 2020, 17, 656-672. [CrossRef] [PubMed]

5. Brown, J.C.; Gerhardt, T.E.; Kwon, E. Risk Factors For Coronary Artery Disease. StatPearls 2021. Available online: https:/ pubmed. ncbi.nlm.nih.gov/32119297/ (accessed on 17 August 2021).

6. Stokes, J., 3rd; Kannel, W.B.; Dawber, T.R.; Kagan, A.; Revotskie, N. Factors of risk in the development of coronary heart disease-six year follow-up experience. The Framingham Study. Ann. Intern. Med. 1961, 55, 33-50.

7. Townsend, N.; Wilson, L.; Bhatnagar, P.; Wickramasinghe, K.; Rayner, M.; Nichols, M. Cardiovascular disease in Europe: Epidemiological update 2016. Eur. Heart J. 2016, 37, 3232-3245. [CrossRef] 
8. Li, X.; Liu, L.; Cao, Z.; Li, W.; Li, H.; Lu, C.; Yang, X.; Liu, Y. Gut microbiota as an "invisible organ" that modulates the function of drugs. Biomed. Pharmacother. 2020, 121, 109653. [CrossRef]

9. Clarke, G.; Stilling, R.M.; Kennedy, P.J.; Stanton, C.; Cryan, J.F.; Dinan, T.G. Minireview: Gut microbiota: The neglected endocrine organ. Mol. Endocrinol. 2014, 28, 1221-1238. [CrossRef]

10. Kayama, H.; Okumura, R.; Takeda, K. Interaction Between the Microbiota, Epithelia, and Immune Cells in the Intestine. Annu Rev. Immunol. 2020, 38, 23-48. [CrossRef]

11. Qin, J.; Li, Y.; Cai, Z.; Li, S.; Zhu, J.; Zhang, F.; Liang, S.; Zhang, W.; Guan, Y.; Shen, D.; et al. A metagenome-wide association study of gut microbiota in type 2 diabetes. Nature 2012, 490, 55-60. [CrossRef]

12. Rothschild, D.; Weissbrod, O.; Barkan, E.; Kurilshikov, A.; Korem, T.; Zeevi, D.; Costea, P.I.; Godneva, A.; Kalka, I.N.; Bar, N.; et al. Environment dominates over host genetics in shaping human gut microbiota. Nature 2018, 555, 210-215. [CrossRef] [PubMed]

13. Turnbaugh, P.J.; Ley, R.E.; Mahowald, M.A.; Magrini, V.; Mardis, E.R.; Gordon, J.I. An obesity-associated gut microbiome with increased capacity for energy harvest. Nature 2006, 444, 1027-1031. [CrossRef] [PubMed]

14. Bäckhed, F.; Ley, R.E.; Sonnenburg, J.L.; Peterson, D.A.; Gordon, J.I. Host-bacterial mutualism in the human intestine. Science 2005, 307, 1915-1920. [CrossRef] [PubMed]

15. Xu, J.; Gordon, J.I. Honor thy symbionts. Proc. Natl. Acad. Sci. USA. 2003, 100, 10452-10459. [CrossRef] [PubMed]

16. Chow, J.; Lee, S.M.; Shen, Y.; Khosravi, A.; Mazmanian, S.K. Host-bacterial symbiosis in health and disease. Adv. Immunol. 2010, 107, 243-274.

17. Witkowski, M.; Weeks, T.L.; Hazen, S.L. Gut Microbiota and Cardiovascular Disease. Circ. Res. 2020, 127, 553-570. [CrossRef]

18. Battson, M.L.; Lee, D.M.; Weir, T.L.; Gentile, C.L. The gut microbiota as a novel regulator of cardiovascular function and disease. J. Nutr. Biochem. 2018, 56, 1-15. [CrossRef]

19. Koliada, A.; Syzenko, G.; Moseiko, V.; Budovska, L.; Puchkov, K.; Perederiy, V.; Gavalko, Y.; Dorofeyev, A.; Romanenko, M.; Tkach, S.; et al. Association between body mass index and Firmicutes/Bacteroidetes ratio in an adult Ukrainian population. BMC Microbiol. 2017, 17, 120. [CrossRef]

20. Khan, M.J.; Gerasimidis, K.; Edwards, C.A.; Shaikh, M.G.J. Role of gut microbiota in the aetiology of obesity: Proposed mechanisms and review of the literature. Obesity 2016, 2016, 7353642. [CrossRef]

21. Ridaura, V.K.; Faith, J.J.; Rey, F.E.; Cheng, J.; Duncan, A.E.; Kau, A.L.; Griffin, N.W.; Lombard, V.; Henrissat, B.; Bain, J.R.; et al. Gut microbiota from twins discordant for obesity modulate metabolism in mice. Science 2013, 341, 1241214. [CrossRef]

22. Nicolucci, A.C.; Hume, M.P.; Martínez, I.; Mayengbam, S.; Walter, J.; Reimer, R.A. Prebiotics Reduce Body Fat and Alter Intestinal Microbiota in Children Who Are Overweight or With Obesity. Gastroenterology 2017, 153, 711-722. [CrossRef]

23. Gomes, A.C.; Hoffmann, C.; Mota, J.F. The human gut microbiota: Metabolism and perspective in obesity. Rev. Gut Microbes 2018, 9, 308-325. [CrossRef] [PubMed]

24. Fu, J.; Bonder, M.J.; Cenit, M.C.; Tigchelaar, E.F.; Maatman, A.; Dekens, J.A.; Brandsma, E.; Marczynska, J.; Imhann, F.; Weersma, R.K.; et al. The Gut Microbiome Contributes to a Substantial Proportion of the Variation in Blood Lipids. Circ. Res. 2015, 117, 817-824. [CrossRef] [PubMed]

25. Gérard, P.; Lepercq, P.; Leclerc, M.; Gavini, F.; Raibaud, P.; Juste, C. Bacteroides sp. strain D8, the first cholesterol-reducing bacterium isolated from human feces. Appl. Environ. Microbiol. 2007, 73, 5742-5749. [CrossRef] [PubMed]

26. Freier, T.A.; Beitz, D.C.; Li, L.; Hartman, P.A. Characterization of Eubacterium coprostanoligenes sp. nov., a cholesterol-reducing anaerobe. Int. J. Syst. Bacteriol. 1994, 44, 137-142. [CrossRef] [PubMed]

27. Lye, H.S.; Rusul, G.; Liong, M.T. Removal of cholesterol by lactobacilli via incorporation and conversion to coprostanol. J. Dairy Sci. 2010, 93, 1383-1392. [CrossRef] [PubMed]

28. Wu, Y.; Zhang, Q.; Ren, Y.; Ruan, Z. Effect of probiotic Lactobacillus on lipid profile: A systematic review and meta-analysis of randomized, controlled trials. PLoS ONE 2017, 12, e0178868. [CrossRef]

29. Schaafsma, G.; Meuling, W.J.A.; Van Dokkum, W.; Bouley, C. Effects of a milk product, fermented by Lactobacillus acidophilus and with fructo-oligosaccharides added, on blood lipids in male volunteers. Eur. J. Clin. Nutr. 1998, 52, 436-440. [CrossRef]

30. Bertolami, M.C.; Faludi, A.A.; Batlouni, M. Evaluation of the effects of a new fermented milk product (Gaio) on primary hypercholesterolemia. Eur. J. Clin. Nutr. 1999, 53, 97-101. [CrossRef]

31. Ruscica, M.; Pavanello, C.; Gandini, S.; Macchi, C.; Botta, M.; Dall'Orto, D.; Del Puppo, M.; Bertolotti, M.; Bosisio, R.; Mombelli, G.; et al. Nutraceutical approach for the management of cardiovascular risk-A combination containing the probiotic Bifidobacterium longum BB536 and red yeast rice extract: Results from a randomized, double-blind, placebo-controlled study. Nutr. J. 2019, 18, 13. [CrossRef]

32. Rebolledo, C.; Cuevas, A.; Zambrano, T.; Acuña, J.J.; Jorquera, M.A.; Saavedra, K.; Martínez, C.; Lanas, F.; Serón, P.; Salazar, L.A.; et al. Bacterial Community Profile of the Gut Microbiota Differs between Hypercholesterolemic Subjects and Controls. Biomed. Res. Int. 2017, 2017, 8127814. [CrossRef]

33. Just, S.; Mondot, S.; Ecker, J.; Wegner, K.; Rath, E.; Gau, L.; Streidl, T.; Hery-Arnaud, G.; Schmidt, S.; Lesker, T.R.; et al. The gut microbiota drives the impact of bile acids and fat source in diet on mouse metabolism. Microbiome 2018, 6, 134. [CrossRef] [PubMed]

34. Jones, M.L.; Martoni, C.J.; Prakash, S. Cholesterol lowering and inhibition of sterol absorption by Lactobacillus reuteri NCIMB 30242: A randomized controlled trial. Eur. J. Clin. Nutr. 2012, 66, 1234-1241. [CrossRef] [PubMed] 
35. Savin, Z.; Kivity, S.; Yonath, H.; Yehuda, S. Smoking and the intestinal microbiome. Arch. Microbiol. 2018, 200, 677-684. [CrossRef] [PubMed]

36. Nolan-Kenney, R.; Wu, F.; Hu, J.; Yang, L.; Kelly, D.; Li, H.; Jasmine, F.; Kibriya, M.G.; Parvez, F.; Shaheen, I.; et al. The association between smoking and gut microbiome in Bangladesh. Nicotine Tob. Res. 2020, 22, 1339-1346. [CrossRef] [PubMed]

37. Lee, S.H.; Yun, Y.; Kim, S.J.; Lee, E.J.; Chang, Y.; Ryu, S.; Shin, H.; Kim, H.L.; Kim, H.N.; Lee, J.H. Association between Cigarette Smoking Status and Composition of Gut Microbiota: Population-Based Cross-Sectional Study. J. Clin. Med. 2018, 7, 282. [CrossRef]

38. Stewart, C.J.; Auchtung, T.A.; Ajami, N.J.; Velasquez, K.; Smith, D.P.; De La Garza, R., 2nd; Salas, R.; Petrosino, J.F. Effects of tobacco smoke and electronic cigarette vapor exposure on the oral and gut microbiota in humans: A pilot study. PeerJ 2018, 6, e4693. [CrossRef]

39. McLean, C.; Jun, S.; Kozyrskyj, A. Impact of maternal smoking on the infant gut microbiota and its association with child overweight: A scoping review. World J. Pediatr. 2019, 15, 341-349. [CrossRef]

40. Clarke, S.F.; Murphy, E.F.; O’Sullivan, O.; Lucey, A.J.; Humphreys, M.; Hogan, A.; Hayes, P.; O’Reilly, M.; Jeffery, I.B.; Wood-Martin, R.; et al. Exercise and associated dietary extremes impact on gut microbial diversity. Gut 2014, 63, 1913-1920. [CrossRef]

41. Dao, M.C.; Everard, A.; Aron-Wisnewsky, J.; Sokolovska, N.; Prifti, E.; Verger, E.O.; Kayser, B.D.; Levenez, F.; Chilloux, J.; Hoyles, L.; et al. Akkermansia muciniphila and improved metabolic health during a dietary intervention in obesity: Relationship with gut microbiome richness and ecology. Gut 2016, 65, 426-436. [CrossRef]

42. Barton, W.; Penney, N.C.; Cronin, O.; Garcia-Perez, I.; Molloy, M.G.; Holmes, E.; Shanahan, F.; Cotter, P.D.; O’Sullivan, O. The microbiome of professional athletes differs from that of more sedentary subjects in composition and particularly at the functional metabolic level. Gut 2018, 67, 625-633. [CrossRef]

43. Mailing, L.J.; Allen, J.M.; Buford, T.W.; Fields, C.J.; Woods, J.A. Exercise and the Gut Microbiome: A Review of the Evidence, Potential Mechanisms, and Implications for Human Health. Exerc. Sport Sci. Rev. 2019, 47, 75-85. [CrossRef] [PubMed]

44. Morita, E.; Yokoyama, H.; Imai, D.; Takeda, R.; Ota, A.; Kawai, E.; Hisada, T.; Emoto, M.; Suzuki, Y.; Okazaki, K. Aerobic Exercise Training with Brisk Walking Increases Intestinal Bacteroides in Healthy Elderly Women. Nutrients 2019, 11, 868. [CrossRef] [PubMed]

45. Motiani, K.K.; Collado, M.C.; Eskelinen, J.J.; Virtanen, K.A.; Löyttyniemi, E.; Salminen, S.; Nuutila, P.; Kalliokoski, K.K.; Hannukainen, J.C. Exercise Training Modulates Gut Microbiota Profile and Improves Endotoxemia. Med. Sci. Sports Exerc. 2020, 52, 94-104. [CrossRef] [PubMed]

46. Mariat, D.; Firmesse, O.; Levenez, F.; Guimarăes, V.; Sokol, H.; Doré, J.; Corthier, G.; Furet, J.P. The Firmicutes/Bacteroidetes ratio of the human microbota changes with age. BMC Microbiol. 2009, 9, 123. [CrossRef] [PubMed]

47. Odamaki, T.; Kato, K.; Sugahara, H.; Hashikura, N.; Takahashi, S.; Xiao, J.Z.; Abe, F.; Osawa, R. Age-related changes in gut microbiota composition from newborn to centenarian: A cross-sectional study. BMC Microbiol. 2016, 16, 90. [CrossRef]

48. Kato, K.; Odamaki, T.; Mitsuyama, E.; Sugahara, H.; Xiao, J.Z.; Osawa, R. Age-Related Changes in the Composition of Gut Bifidobacterium Species. Curr. Microbiol. 2017, 74, 987-995. [CrossRef]

49. Wang, F.; Yu, T.; Huang, G.; Cai, D.; Liang, X.; Su, H.; Zhu, Z.; Li, D.; Yang, Y.; Shen, P.; et al. Gut microbiota community and its assembly associated with age and diet in Chinese centenarians. J. Microbiol. Biotechnol. 2015, 25, 1195-1204. [CrossRef]

50. Salazar, N.; Arboleya, S.; Fernández-Navarro, T.; de Los Reyes-Gavilán, C.G.; Gonzalez, S.; Gueimonde, M. Age-Associated Changes in Gut Microbiota and Dietary Components Related with the Immune System in Adulthood and Old Age: A CrossSectional Study. Nutrients 2019, 11, 1765. [CrossRef]

51. Takagi, T.; Naito, Y.; Inoue, R.; Kashiwagi, S.; Uchiyama, K.; Mizushima, K.; Tsuchiya, S.; Dohi, O.; Yshida, N.; Kamada, K.; et al. Differences in gut microbiota associated with age, sex, and stool consistency in healthy Japanese subjects. J. Gastroenterol. 2019, 54, 53-63. [CrossRef]

52. Dominianni, C.; Sinha, R.; Goedert, J.J.; Pei, Z.; Yang, L.; Hayes, R.B. Sex, body mass index, and dietary fiber intake influence the human gut microbiome. PLoS ONE 2015, 10, e0124599. [CrossRef]

53. Li, M.; Wang, B.; Zhang, M.; Rantalainen, M.; Wang, S.; Zhou, H.; Zhang, Y.; Shen, J.; Pang, X.; Zhang, M.; et al. Symbiotic gut microbes modulate human metabolic phenotypes. Proc. Natl. Acad. Sci. USA 2008, 105, 2117-2122. [CrossRef] [PubMed]

54. Mueller, S.; Saunier, K.; Hanisch, C.; Norin, E.; Alm, L.; Midtvedt, T.; Cresci, A.; Silvi, S.; Orpianesi, C.; Verdenelli, M.C.; et al. Differences in fecal microbiota in different European study populations in relation to age, gender, and country: A cross-sectional study. Appl. Environ. Microbiol. 2006, 72, 1027-1033. [CrossRef] [PubMed]

55. Haro, C.; Rangel-Zúñiga, O.A.; Alcalá-Díaz, J.F.; Gómez-Delgado, F.; Pérez-Martínez, P.; Delgado-Lista, J.; Quintana-Navarro, G.M.; Landa, B.B.; Navas-Cortés, J.A.; Tena-Sempere, M.; et al. Intestinal microbiota is influenced by gender and body mass index. PLoS ONE 2016, 11, e0154090. [CrossRef] [PubMed]

56. Schnorr, S.L.; Candela, M.; Rampelli, S.; Centanni, M.; Consolandi, C.; Basaglia, G.; Turroni, S.; Biagi, E.; Peano, C.; Severgnini, M.; et al. Gut microbiome of the Hadza hunter-gatherers. Nat. Commun. 2014, 5, 3654. [CrossRef] [PubMed]

57. Kopp, W. How Western Diet And Lifestyle Drive The Pandemic Of Obesity And Civilization Diseases. Diabetes Metab. Syndr. Obes. 2019, 12, 2221-2236. [CrossRef]

58. Koliaki, C.; Liatis, S.; Kokkinos, A. Obesity and cardiovascular disease: Revisiting an old relationship. Metabolism 2019, 92, 98-107. [CrossRef]

59. Duca, F.A.; Lam, T.K. Gut microbiota, nutrient sensing and energy balance. Diabetes Obes. Metab. 2014, 16, 68-76. [CrossRef] 
60. De Backer, G.; Ambrosioni, E.; Borch-Johnsen, K.; Brotons, C.; Cifkova, R.; Dallongeville, J.; Ebrahim, S.; Faergeman, O.; Graham, I.; Mancia, G.; et al. Third Joint Task Force of European and other Societies on Cardiovascular Disease Prevention in Clinical Practice: (constituted by representatives of eight societies and by invited experts). Eur. J. Cardiovasc. Prev. Reh. 2003, 10, 1-78.

61. Wong, N.D. Epidemiological studies of CHD and the evolution of preventive cardiology. Nat. Rev. Cardiol. 2014, 11, 276-289. [CrossRef]

62. Leong, K.S.W.; Jayasinghe, T.N.; Derraik, J.G.B.; Albert, B.B.; Chiavaroli, V.; Svirskis, D.M.; Beck, K.L.; Conlon, C.A.; Jiang, Y.; Schierding, W.; et al. Protocol for the Gut Bugs Trial: A randomised double-blind placebo-controlled trial of gut microbiome transfer for the treatment of obesity in adolescents. BMJ Open 2019, 9, e026174. [CrossRef]

63. Park, S.; Bae, J.H. Probiotics for weight loss: A systematic review and meta-analysis. Nutr. Res. 2015, 35, 566-575. [CrossRef]

64. Suzumura, E.A.; Bersch-Ferreira, A.C.; Torreglosa, C.R.; da Silva, J.T.; Coqueiro, A.Y.; Kuntz, M.G.F.; Chrispim, P.P.; Weber, B.; Cavalcanti, A.B. Effects of oral supplementation with probiotics or synbiotics in overweight and obese adults: A systematic review and meta-analyses of randomized trials. Nutr. Rev. 2019, 77, 430-450. [CrossRef]

65. Louis, P.; Flint, H.J. Formation of propionate and butyrate by the human colonic microbiota. Environ. Microbiol. 2017, 19, 29-41. [CrossRef]

66. Ley, R.E.; Turnbaugh, P.J.; Klein, S.; Gordon, J.I. Microbial ecology: Human gut microbes associated with obesity. Nature 2006, 444, 1022-1023. [CrossRef]

67. Schwiertz, A.; Taras, D.; Schafer, K.; Beijer, S.; Bos, N.A.; Donus, C.; Hardt, P.D. Microbiota and SCFA in lean and overweight healthy subjects. Obesity 2010, 18, 190-195. [CrossRef]

68. Chen, X.F.; Chen, X.; Tang, X. Short-chain fatty acid, acylation and cardiovascular diseases. Clin. Sci. 2020, 134, 657-676. [CrossRef]

69. Poll, B.G.; Xu, J.; Jun, S.; Sanchez, J.; Zaidman, N.A.; He, X.; Lester, L.; Berkowitz, D.E.; Paolocci, N.; Gao, W.D.; et al. Acetate, a Short-Chain Fatty Acid, Acutely Lowers Heart Rate and Cardiac Contractility Along with Blood Pressure. J. Pharmacol. Exp. Ther. 2021, 377, 39-50. [CrossRef]

70. Pluznick, J.L.; Protzko, R.J.; Gevorgyan, H.; Peterlin, Z.; Sipos, A.; Han, J.; Brunet, I.; Wan, L.X.; Rey, F.; Wang, T.; et al. Olfactory receptor responding to gut microbiota-derived signals plays a role in renin secretion and blood pressure regulation. Proc. Natl. Acad. Sci. USA 2013, 110, 4410-4415. [CrossRef]

71. Bartolomaeus, H.; Balogh, A.; Yakoub, M.; Homann, S.; Markó, J.; Höges, S.; Tsvetkov, D.; Krannichz, A.; Wundersitz, S.; Avery, E.G.; et al. Short-Chain Fatty Acid Propionate Protects From Hypertensive Cardiovascular Damage. Circulation 2019, 139, 1407-1421. [CrossRef]

72. Aguilar, E.C.; Leonel, A.J.; Teixeira, L.G.; Silva, A.R.; Silva, J.F.; Pelaez, J.M.; Capettini, L.S.; Lemos, V.S.; Santos, R.A.; Alvarez-Leite, J.I. Butyrate impairs atherogenesis by reducing plaque inflammation and vulnerability and decreasing NFkappaB activation. Nutr. Metab. Cardiovasc. Dis. 2014, 24, 606-613. [CrossRef]

73. Chen, Y.; Du, J.; Zhao, Y.T.; Zhang, L.; Lv, G.; Zhuang, S.; Qin, G.; Zhao, T.C. Histone deacetylase (HDAC) inhibition improves myocardial function and prevents cardiac remodeling in diabetic mice. Cardiovasc. Diabetol. 2015, 14, 99. [CrossRef] [PubMed]

74. Wei, F.; Lamichhane, S.; Orešič, M.; Hyötyläinen, T. Lipidomes in health and disease: Analytical strategies and considerations. TrAC Trends Anal. Chem. 2019, 120, 115664. [CrossRef]

75. Lamichhane, S.; Sen, P.; Alves, M.A.; Ribeiro, H.C.; Raunioniemi, P.; Hyötyläinen, T.; Orešič, M. Linking Gut Microbiome and Lipid Metabolism: Moving beyond Associations. Metabolites 2021, 11, 55. [CrossRef]

76. Tran, T.T.; Postal, B.G.; Demignot, S.; Ribeiro, A.; Osinski, C.; Pais de Barros, J.P.; Blachnio-Zabielska, A.; Leturque, A.; Rousset, M.; Ferré, P.; et al. Short Term Palmitate Supply Impairs Intestinal Insulin Signaling via Ceramide Production. J. Biol. Chem. 2016, 291, 16328-16338. [CrossRef]

77. Iqbal, J.; Hussain, M.M. Intestinal lipid absorption. Am. J. Physiol. Endocrinol. Metab. 2009, 296, 1183-1194. [CrossRef]

78. Kenny, D.J.; Plichta, D.R.; Shungin, D.; Koppel, N.; Hall, A.B.; Fu, B.; Vasan, R.S.; Shaw, S.Y.; Vlamakis, H.; Balskus, E.P.; et al. Cholesterol Metabolism by Uncultured Human Gut Bacteria Influences Host Cholesterol Level. Cell Host Microbes 2020, 28, 245-257. [CrossRef]

79. Schoeler, M.; Caesar, R. Dietary lipids, gut microbiota and lipid metabolism. Rev Endocr. Metab. Disord. 2019, $20,461-472$. [CrossRef]

80. Liu, Y.; Song, X.; Zhou, H.; Zhou, X.; Xia, Y.; Dong, X.; Zhong, W.; Tang, S.; Wang, L.; Wen, S.; et al. Gut Microbiome Associates with Lipid-Lowering Effect of Rosuvastatin in Vivo. Front. Microbiol. 2018, 9, 530. [CrossRef]

81. Kim, M.; Gu, B.; Madison, M.C.; Song, H.W.; Norwood, K.; Hill, A.A.; Wu, W.J.; Corry, D.; Kheradmand, F.; Diehl, G.E. Cigarette Smoke Induces Intestinal Inflammation via a Th17 Cell-Neutrophil Axis. Front. Immunol. 2019, 10, 75. [CrossRef]

82. Gil-Cruz, C.; Perez-Shibayama, C.; De Martin, A.; Ronchi, F.; van der Borght, K.; Niederer, R.; Onder, L.; Lütge, M.; Novkovic, M.; Nindl, V.; et al. Microbiota-derived peptide mimics drive lethal inflammatory cardiomyopathy. Science 2019, 366, 881-886. [CrossRef]

83. Li, J.; Zhao, F.; Wang, Y.; Chen, J.; Tao, J.; Tian, G.; Wu, S.; Liu, W.; Cui, Q.; Geng, B.; et al. Gut microbiota dysbiosis contributes to the development of hypertension. Microbiome 2017, 5, 14. [CrossRef] [PubMed]

84. Kelly, T.N.; Bazzano, L.A.; Ajami, N.J.; He, H.; Zhao, J.; Petrosino, J.F.; Correa, A.; He, J. Gut Microbiome Associates With Lifetime Cardiovascular Disease Risk Profile Among Bogalusa Heart Study Participants. Circ. Res. 2016, 119, 956-964. [CrossRef] [PubMed] 
85. Liu, Z.; Li, J.; Liu, H.; Tang, Y.; Zhan, Q.; Lai, W.; Ao, L.; Meng, X.; Ren, H.; Xu, D.; et al. The intestinal microbiota associated with cardiac valve calcification differs from that of coronary artery disease. Atherosclerosis 2019, 284, 121-128. [CrossRef] [PubMed]

86. Shin, J.H.; Sim, M.; Lee, J.Y.; Shin, D.M. Lifestyle and geographic insights into the distinct gut microbiota in elderly women from two different geographic locations. J. Physiol. Anthropol. 2016, 35, 31. [CrossRef]

87. Chmielewski, T.; Kuśmierczyk, M.; Fiecek, B.; Roguska, U.; Lewandowska, G.; Parulski, A.; Cielecka-Kuszyk, J.; TylewskaWierzbanowska, S. Tick-borne pathogens Bartonella spp., Borrelia burgdorferi sensu lato, Coxiella burnetii and Rickettsia spp. may trigger endocarditis. Adv. Clin. Exp. Med. 2019, 28, 937-943. [CrossRef]

88. Tun, H.M.; Bridgman, S.L.; Chari, R.; Field, C.J.; Guttman, D.S.; Becker, A.B.; Mandhane, P.J.; Turvey, S.E.; Subbarao, P.; Sears, M.R.; et al. Roles of birth mode and infant gut microbiota in intergenerational transmission of overweight and obesity from mother to ofspring. JAMA Pediatr. 2018, 172, 368-377. [CrossRef]

89. Lavie, C.J.; Ozemek, C.; Carbone, S.; Katzmarzyk, P.T.; Blair, S.N. Sedentary Behavior, Exercise, and Cardiovascular Health. Circ. Res. 2019, 124, 799-815. [CrossRef]

90. Dalton, A.; Mermier, C.; Zuhl, M. Exercise influence on the microbiome-gut-brain axis. Gut Microbes 2019, 10, 555-568. [CrossRef]

91. Mitchell, C.M.; Davy, B.M.; Hulver, M.W.; Neilson, A.P.; Bennett, B.; Davy, K.P. Does Exercise Alter Gut Microbial Composition? A Systematic Review. Med. Sci. Sports Exerc. 2019, 51, 160-167. [CrossRef]

92. Naito, Y.; Uchiyama, K.; Takagi, T. A next-generation beneficial microbe: Akkermansia muciniphila. J. Clin. Biochem. Nutr. 2018, 63, 33-35. [CrossRef]

93. Xu, Y.; Wang, N.; Tan, H.-Y.; Li, S.; Zhang, C.; Feng, Y. Function of Akkermansia muciniphila in Obesity: Interactions With Lipid Metabolism, Immune Response and Gut Systems. Front. Microbiol. 2020, 11, 219. [CrossRef] [PubMed]

94. Chelakkot, C.; Choi, Y.; Kim, D.K.; Park, H.T.; Ghim, J.; Kwon, Y.; Jeon, J.; Kim, M.S.; Jee, Y.K.; Gho, Y.S.; et al. Akkermansia muciniphila-derived extracellular vesicles influence gut permeability through the regulation of tight junctions. Exp. Mol. Med. 2018, 50, e450. [CrossRef] [PubMed]

95. Ashrafian, F.; Behrouzi, A.; Shahriary, A.; Ahmadi Badi, S.; Davari, M.; Khatami, S.; Rahimi Jamnani, F.; Fateh, A.; Vaziri, F.; Siadat, S.D. Comparative study of effect of Akkermansia muciniphila and its extracellular vesicles on toll-like receptors and tight junction. Gastroenterol. Hepatol. Bed. Bench. 2019, 12, 163-168. [PubMed]

96. Everard, A.; Belzer, C.; Geurts, L.; Ouwerkerk, J.P.; Druart, C.; Bindels, L.B.; Guiot, Y.; Derrien, M.; Muccioli, G.G.; Delzenne, N.M.; et al. Cross-talk between Akkermansia muciniphila and intestinal epithelium controls diet-induced obesity. Proc. Natl. Acad. Sci. USA 2013, 110, 9066-9071. [CrossRef]

97. Tilg, H.; Moschen, A.R. Microbiota and diabetes: An evolving relationship. Gut 2014, 63, 1513-1521. [CrossRef]

98. Verhaar, B.J.H.; Collard, D.; Prodan, A.; Levels, J.H.M.; Zwinderman, A.H.; Bäckhed, F.; Vogt, L.; Peters, M.J.L.; Muller, M.; Nieuwdorp, M.; et al. Associations between gut microbiota, faecal short-chain fatty acids, and blood pressure across ethnic groups: The HELIUS study. Eur. Heart J. 2020, 41, 4259-4267. [CrossRef]

99. Tamanai-Shacoori, Z.; Smida, I.; Bousarghin, L.; Loreal, O.; Meuric, V.; Fong, S.B.; Bonnaure-Mallet, M.; Jolivet-Gougeon, A. Roseburia spp.: A marker of health? Future Microbiol. 2017, 12, 157-170. [CrossRef]

100. Barcenilla, A.; Pryde, S.E.; Martin, J.C.; Duncan, S.H.; Stewart, C.S.; Henderson, C.; Flint, H.J. Phylogenetic relationships of butyrate-producing bacteria from the human gut. Appl. Environ. Microbiol. 2000, 66, 1654-1661. [CrossRef]

101. Cui, X.; Ye, L.; Li, J.; Jin, L.; Wang, W.; Li, S.; Bao, M.; Wu, S.; Li, L.; Geng, B.; et al. Metagenomic and metabolomic analyses unveil dysbiosis of gut microbiota in chronic heart failure patients. Sci. Rep. 2018, 8, 635. [CrossRef]

102. Kane, A.E.; Howlett, S.E. Differences in Cardiovascular Aging in Men and Women. Adv. Exp. Med. Biol. $2018,1065,389-411$.

103. Matsumoto, M.; Kurihara, S.; Kibe, R.; Ashida, H.; Benno, Y. Longevity in mice is promoted by probiotic-induced suppression of colonic senescence dependent on upregulation of gut bacterial polyamine production. PLoS ONE 2011, 6, 23652. [CrossRef] [PubMed]

104. Fanning, S.; Hall, L.J.; Cronin, M.; Zomera, A.; MacSharrya, J.; Gouldingd, D.; O'Connell Motherway, M.; Shanahana, F.; Nallya, K.; Dougand, G.; et al. Bifidobacterial surface-exopolysaccharide facilitates commensal-host interaction through immune modulation and pathogen protection. Proc. Natl. Acad. Sci. USA 2012, 109, 2108-2113. [CrossRef] [PubMed]

105. Maffei, V.J.; Kim, S.; Blanchard, E.; Luo, M.; Jazwinski, S.M.; Taylor, C.M.; Welsh, D.A. Biological Aging and the Human Gut Microbiota. J. Gerontol. A Biol. Sci. Med. Sci. 2017, 72, 1474-1482. [CrossRef]

106. Akuzawa, N.; Kurabayashi, M. Native valve endocarditis due to Escherichia coli infection: A case report and review of the literature. Rev. BMC Cardiovasc. Disord. 2018, 18, 195. [CrossRef] [PubMed]

107. Oberbach, A.; Friedrich, M.; Lehmann, S.; Schlichting, N.; Kullnick, Y.; Gräber, S.; Buschmann, T.; Hagl, C.; Bagaev, E. Bacterial infiltration in structural heart valve disease. J. Thorac. Cardiovasc. Surg. 2019, 159, 116-124.e4.

108. Hayashi, T.; Yamashita, T.; Watanabe, H.; Kami, K.; Yoshida, N.; Tabata, T.; Emoto, T.; Sasaki, N.; Mizoguchi, T.; Irino, Y.; et al. Gut Microbiome and Plasma Microbiome-Related Metabolites in Patients with Decompensated and Compensated Heart Failure. Circ. J. 2018, 83, 182-192. [CrossRef]

109. Monk, J.M.; Lepp, D.; Wu, W.; Pauls, K.P.; Robinson, L.E.; Power, K.A. Navy and black bean supplementation primes the colonic mucosal microenvironment to improve gut health. J. Nutr. Biochem. 2017, 49, 89-100. [CrossRef]

110. Hao, W.; He, Z.; Zhu, H.; Liu, J.; Kwek, E.; Zhao, Y.; Ma, K.Y.; He, W.-S.; Chen, Z.-Y. Sea buckthorn seed oil reduces blood cholesterol and modulates gut microbiota. Food Funct. 2019, 10, 5669-5681. [CrossRef] 
111. Zhang, Y.; Gu, Y.; Chen, Y.; Huang, Z.; Li, M.; Jiang, W.; Chen, J.; Rao, W.; Luo, S.; Chen, Y.; et al. Dingxin Recipe IV attenuates atherosclerosis by regulating lipid metabolism through LXR- $\alpha$ /SREBP1 pathway and modulating the gut microbiota in ApoE -/mice fed with HFD. J. Ethnopharmacol. 2021, 266, 113436. [CrossRef]

112. Waterhouse, M.; Hope, B.; Krause, L.; Morrison, M.; Protani, M.M.; Zakrzewski, M.; Neale, R.E. Vitamin D and the gut microbiome: A systematic review of in vivo studies. Eur. J. Nutr. 2019, 58, 2895-2910. [CrossRef]

113. Pérez-López, F.R.; Larrad-Mur, L.; Kallen, A.; Chedraui, P.; Taylor, H.S. Gender differences in cardiovascular disease: Hormonal and biochemical influences. Reprod. Sci. 2010, 17, 511-531. [CrossRef] [PubMed]

114. Emoto, T.; Yamashita, T.; Sasaki, N.; Hirota, Y.; Hayashi, T.; So, A.; Kasahara, K.; Yodoi, K.; Matsumoto, T.; Mizoguchi, T.; et al Analysis of gut microbiota in coronary artery disease patients: A possible link between gut microbiota and coronary artery disease. Atheroscler. Thromb. 2016, 23, 908-921. [CrossRef] [PubMed]

115. Liu, L.; He, X.; Feng, Y. Coronary heart disease and intestinal microbiota. Coron. Artery Dis. 2019, 30, 384-389. [CrossRef] [PubMed]

116. Hu, X.F.; Zhang, W.Y.; Wen, Q.; Chen, W.J.; Wang, Z.M.; Chen, J.; Zhu, F.; Liu, K.; Cheng, L.X.; Yang, J.; et al. Fecal microbiota transplantation alleviates myocardial damage in myocarditis by restoring the microbiota composition. Pharmacol. Res. 2019, 139, 412-421. [CrossRef]

117. Alvarez-Sieiro, P.; Montalbán-López, M.; Mu, D.; Kuipers, O.P. Bacteriocins of lactic acid bacteria: Extending the family. Appl. Microbiol. Biotechnol. 2016, 100, 2939-2951. [CrossRef]

118. Danilo, C.A.; Constantopoulos, E.; McKee, L.A.; Chen, H.; Regan, J.A.; Lipovka, Y.; Lahtinen, S.; Stenman, L.K.; Nguyen, T.-V.V.; Doyle, K.P.; et al. Bifidobacterium animalis subsp. lactis 420 mitigates the pathological impact of myocardial infarction in the mouse. Benef. Microbes 2017, 8, 257-269. [CrossRef]

119. Bermudez-Brito, M.; Plaza-Díaz, J.; Muñoz-Quezada, S.; Gómez-Llorente, C.; Gil, A. Probiotic mechanisms of action. Ann. Nutr. Metab. 2012, 61, 160-174. [CrossRef]

120. Walejko, J.M.; Kim, S.; Goel, R.; Handberg, E.M.; Richards, E.M.; Pepine, C.J.; Raizada, M.K. Gut microbiota and serum metabolite differences in African Americans and White Americans with high blood pressure. Int. J. Cardiol. 2018, 271, 336-339. [CrossRef]

121. Tsai, H.J.; Tsai, W.C.; Hung, W.C.; Hung, W.W.; Chang, C.C.; Dai, C.Y.; Tsai, Y.C. Gut Microbiota and Subclinical Cardiovascular Disease in Patients with Type 2 Diabetes Mellitus. Nutrients 2021, 13, 2679. [CrossRef]

122. Mushtaq, N.; Hussain, S.; Zhang, S.; Yuan, L.; Li, H.; Ullah, S.; Wang, Y.; Xu, J. Molecular characterization of alterations in the intestinal microbiota of patients with grade 3 hypertension. Int. J. Mol. Med. 2019, 44, 513-522. [CrossRef]

123. Sawicka-Smiarowska, E.; Bondarczuk, K.; Bauer, W.; Niemira, M.; Szalkowska, A.; Raczkowska, J.; Kwasniewski, M.; Tarasiuk, E.; Dubatowka, M.; Lapinska, M.; et al. Gut Microbiome in Chronic Coronary Syndrome Patients. J. Clin. Med. 2021, 10, 5074. [CrossRef] [PubMed]

124. Morrison, D.J.; Preston, T. Formation of short chain fatty acids by the gut microbiota and their impact on human metabolism. Gut Microbes 2016, 7, 189-200. [CrossRef] [PubMed]

125. Velagapudi, V.R.; Hezaveh, R.; Reigstad, C.S.; Gopalacharyulu, P.; Yetukuri, L.; Islam, S.; Felin, J.; Perkins, R.; Borén, J.; Oresic, M.; et al. The gut microbiota modulates host energy and lipid metabolism in mice. Lipid Res. 2010, 51, 1101-1112. [CrossRef] [PubMed]

126. May, K.S.; den Hartigh, L.J. Modulation of Adipocyte Metabolism by Microbial Short-Chain Fatty Acids. Nutrients 2021, 13, 3666. [CrossRef]

127. Scheppach, W. Effects of short chain fatty acids on gut morphology and function. Gut 1994, 35, 35-38. [CrossRef]

128. Wolever, T.M.; Spadafora, P.; Eshuis, H. Interaction between colonic acetate and propionate in humans. Am. J. Clin. Nutr. 1991, 53, 681-687. [CrossRef]

129. Wolever, T.M.; Brighenti, F.; Royall, D.; Jenkins, A.L.; Jenkins, D.J. Effect of rectal infusion of short chain fatty acids in human subjects. Am. J. Gastroenterol. 1989, 84, 1027-1033.

130. Frost, G.; Sleeth, M.L.; Sahuri-Arisoylu, M.; Lizarbe, B.; Cerdan, S.; Brody, L.; Anastasovska, J.; Ghourab, S.; Hankir, M.; Zhang, S.; et al. The short-chain fatty acid acetate reduces appetite via a central homeostatic mechanism. Nat. Commun. 2014, 5, 3611. [CrossRef]

131. Sawicka-Śmiarowska, E.; Moniuszko-Malinowska, A.; Kamiński, K.A. Which Microbes Like My Diet and What Does It Mean for My Heart? Nutrients 2021, 13, 4146. [CrossRef] 